\title{
Color and Its Impact on People in the Workplace: A Systematic Review
}

\author{
Hamed Amani ${ }^{1}$ (D), Seyed Hossein Shojaei², Hemn Zarei $^{3}$
}

1. Department of Handicrafts, Faculty of Art \&Architecture, University of Kurdistan, Kurdistan, Iran

2. MSc Student, Department of Occupational Therapy, School of Rehabilitation sciences, Shahid Beheshti University of Medical Sciences, Tehran, Iran

3. MSc Student, Department of Occupational Health Engineering, School of Health, Ahvaz Jundishapur University of Medical Sciences, Ahvaz, Iran

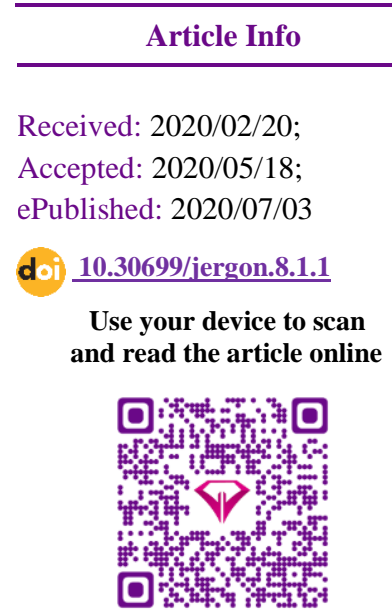

Corresponding Author

Hemn Zarei

Department of Occupational

Health Engineering, School of

Health, Ahvaz Jundishapur

University of Medical Sciences,

Ahvaz, Iran

Tel: 09185179892

Email:

Hemnzarei73@gmail.com

\section{ABSTRACT}

Background and Objectives: A good work environment is a place where one can feel relaxed and focused. In the field of environmental psychology, color is one of the environmental factors that greatly influence human perception and behavior. The purpose of this systematic review study was to investigate the effect of color on work environment.

Methods: This article is a systematic review study. Full-text and Englishlanguage articles published in PubMed, Scopus, Science Direct, Google Scholar were searched using the following keywords: Color perception, color ergonomics, color psychology, color effect, mental health and Workplace. The search was without time limit, and 45 eligible articles were reviewed.

Results: Initially, 262 articles were identified from different databases. Among them, 93 articles met the criteria for entering the study. After that, 48 articles were removed from the study due to lack of experimental studies and 45 articles were selected for final review. A total of 18 studies focused on color priority, 25 studies on mood and emotions, 6 studies on health outcomes, and 19 studies on the effect of workplace color on work-related outcomes. The results showed that color has a significant effect on emotions (eg mood), well-being (eg stress, comfort, well-being) and performance (eg productivity, creativity).

Conclusion: Workplace color should be considered as one of the main ways to promote the (mental and physical) health of individuals.

Keywords: Color perception, Color ergonomics, Color psychology, Color effects, Mental health, Workplace

Copyright (C) 2020, This is an original open-access article distributed under the terms of the Creative Commons Attribution-noncommercial 4.0 International License which permits copy and redistribute of the material just in noncommercial usages with proper citation.

\section{How to Cite This Article:}

Zarei H, Shojaei H, Amani H. Color and Its Impact on People in the Workplace: A Systematic Review Article. Iran J Ergon. 2020; 8 (1) :8-11 


\section{رنتَ و تاثير آن بر افراد در محيط كار: مقالةٔ مرورى نظامند}

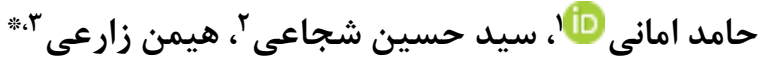

$$
\begin{aligned}
& \text { '. .هيئت علمى كروه صنايع دستى، دانشكده هنر و معمارى، دانشكاه كردستان، كردستان، ايران }
\end{aligned}
$$

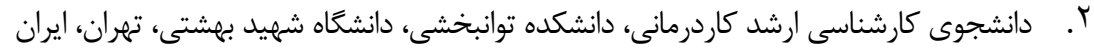

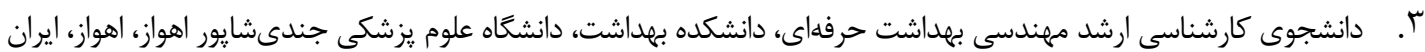

\begin{tabular}{|c|c|}
\hline خلاصه & اطلاعات مقاله \\
\hline 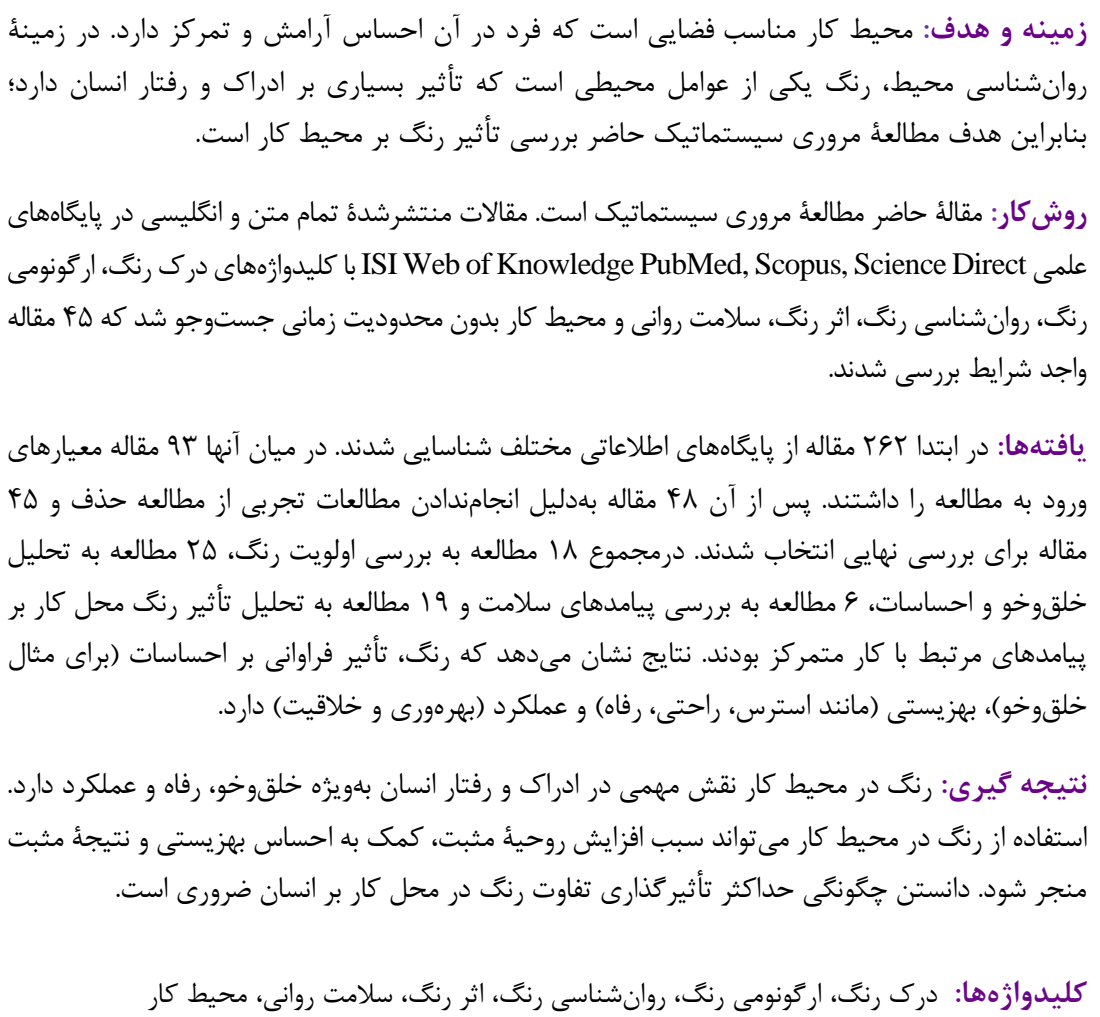 & 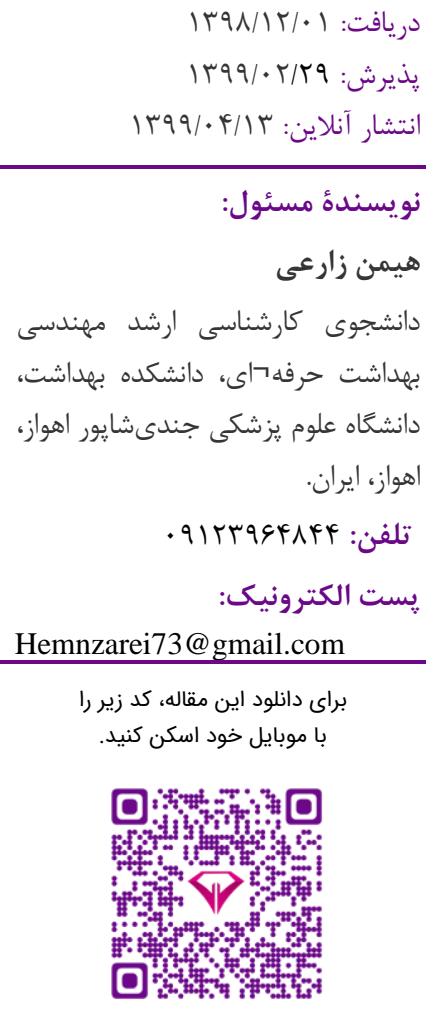 \\
\hline
\end{tabular}

مقدمه

عناصرى است كه در طراحى داخلى، بهويزه در محيط كار نقش

$$
\text { بسزايى دارد [1]. }
$$

در زمينه روانشناسى محيط، رنغ يكى از عوامل محيطى

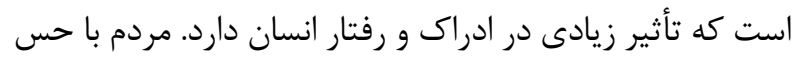

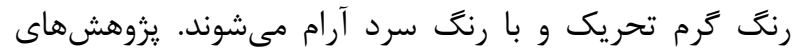

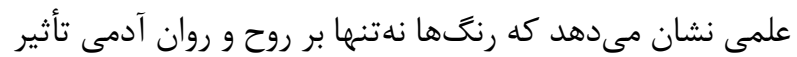

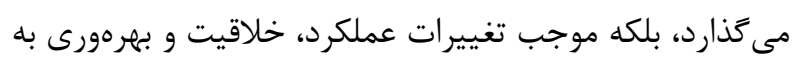

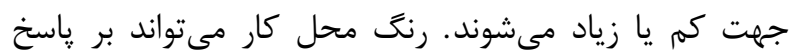

محيط كار مناسب بايد فضايى باشد كه فرد در آن احساس

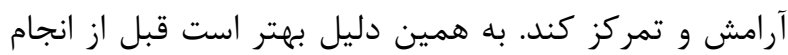

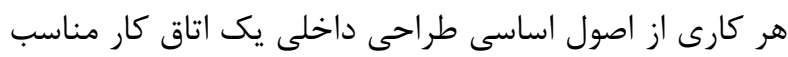

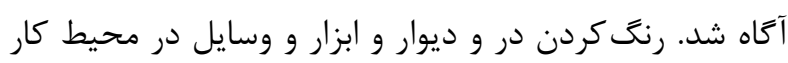
به رنتهاى خاص، سبب افزايش كارايى فرد در محيط

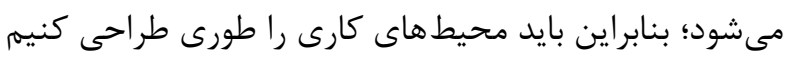

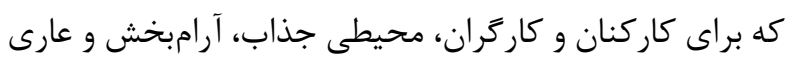

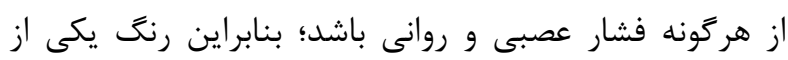


مىشوند، اما در بيشتر مباحث، اصلىترين رنتها آبى، قرمز و

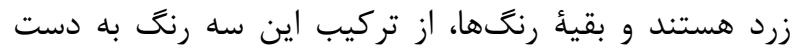

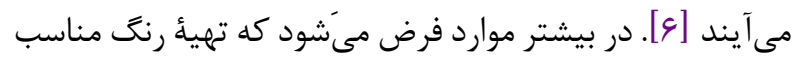
مى تواند تأثيرات مثبتى در محيط كار داشته باشد. علاوه بر اين،

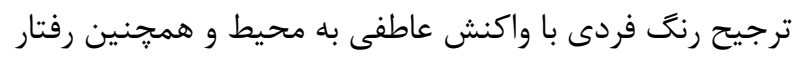

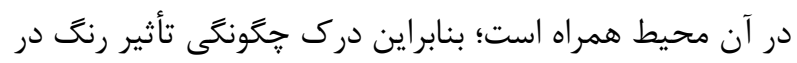
ادراى و رفتار انسان براى ايجاد محيط كار كارآمد ضرورى است.

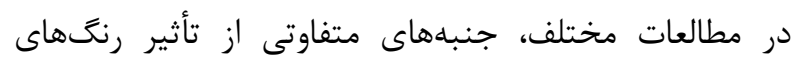

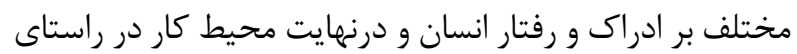
رسيدن به بهرهورى بيشتر بررسى شده است؛ بنابراين هدف رهان

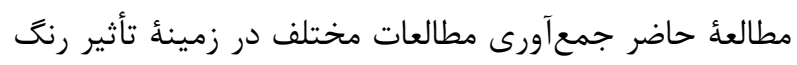
بر محيط كار و ارائُٔ آنها در قالب مطالعهُ مرور سيستماتيك است.

\section{روش كار}

اين مطالعه به روش مرورى سيستماتيك به بررسى رنت و تأثير

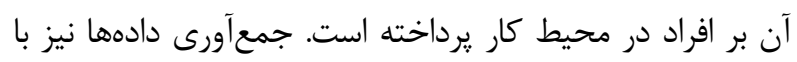

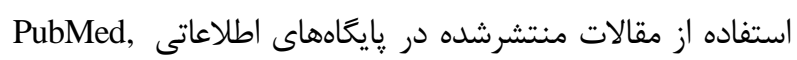
Scopus, ScienceDirect,Google Scholar مقالات بدون هيجزَّنه نظر سوكرايانه انتخاب شدهاند. جستوجوى

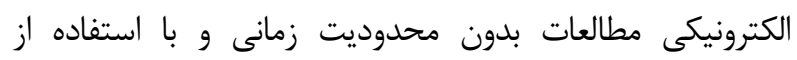
كليدوازمهاى Color Perception, Color Ergonomics, Color در Psychology, Color Effect, Mental Health and Workplace زمينهُ روانشناسى، علوم اجتماعى، معمارى و ارگونومى در عنوان مقالات صورت گرفت. مطالعاتى مدنظر قرار گرفت كه تأثيرات

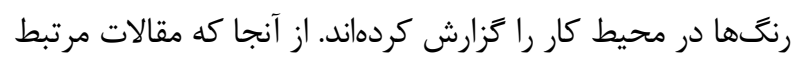

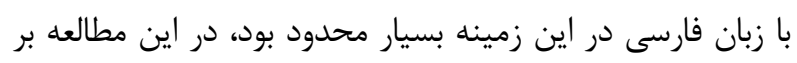
مقالات انگليسى و منتشرشده در نشريات بينالمللى تمركز شد. در در درد

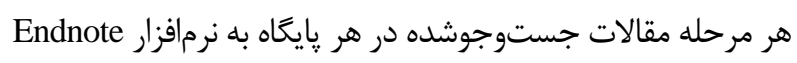

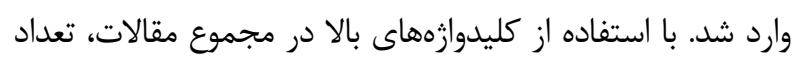

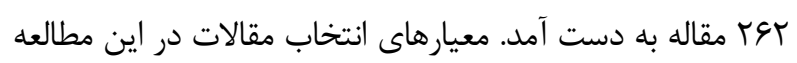

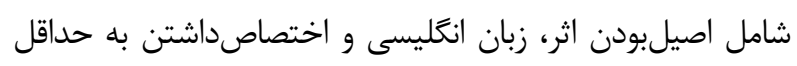

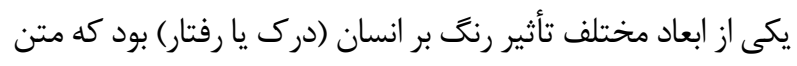
آن قابلدسترس باشد. معيارهاى خروج از مطالعه شامل مقالات

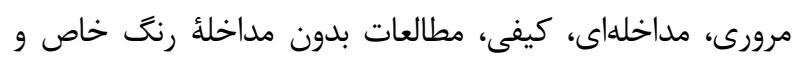

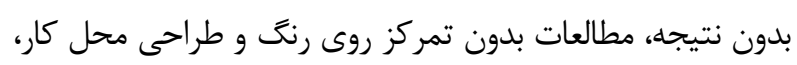

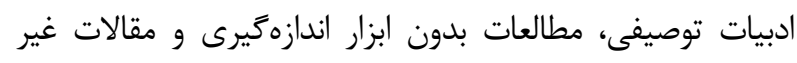

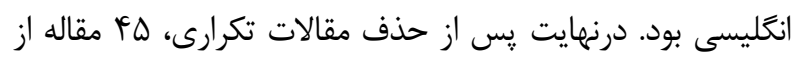

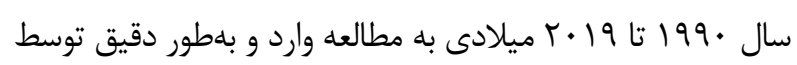

فيزيولوزيكى مانند ضربان قلب و همجنين اضطراب و آسايش

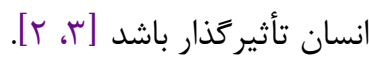

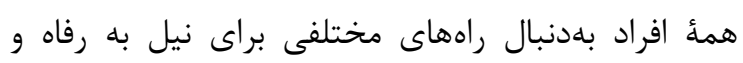

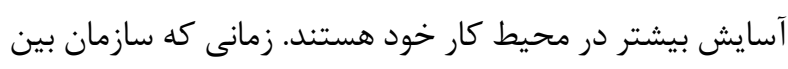

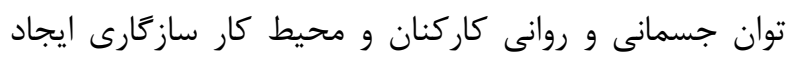

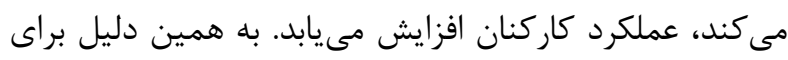

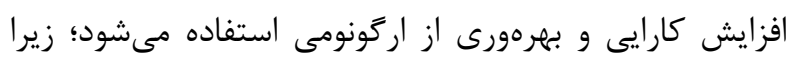

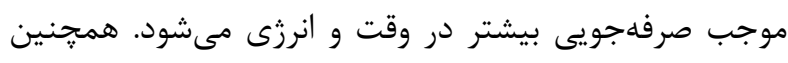

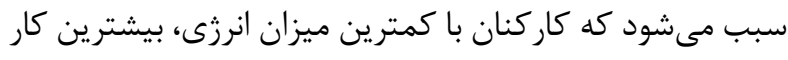

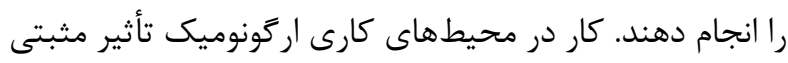

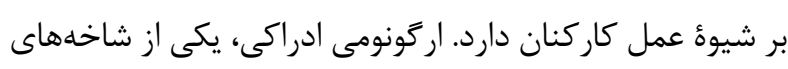

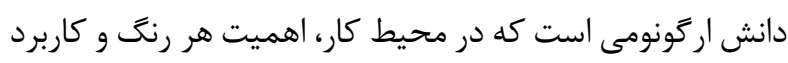

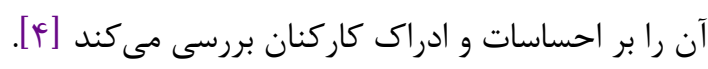

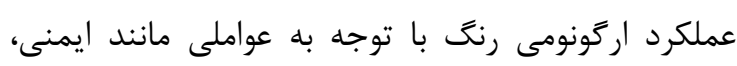

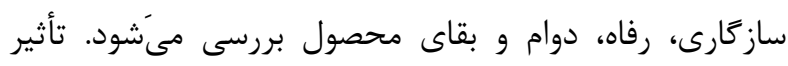

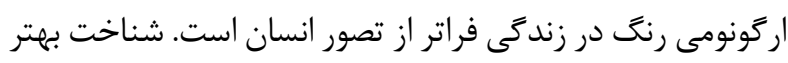

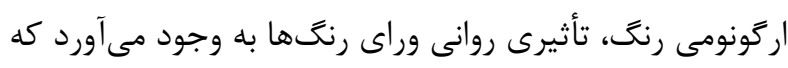

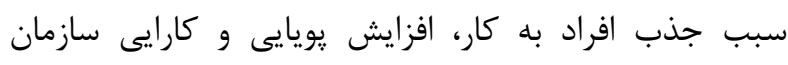

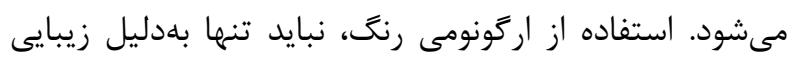

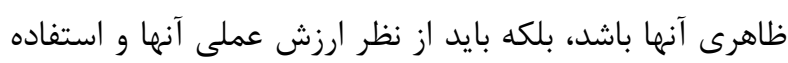

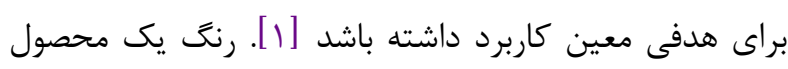

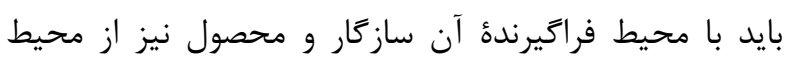

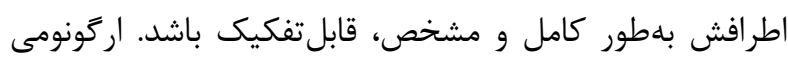

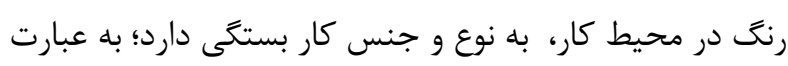

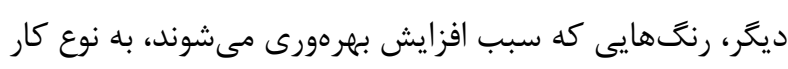

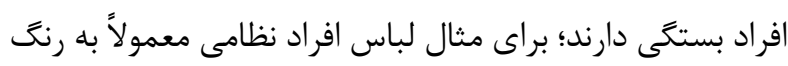

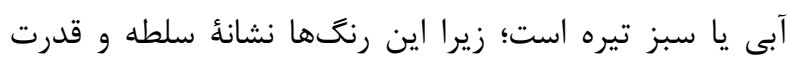

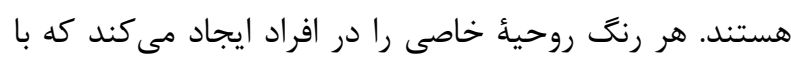

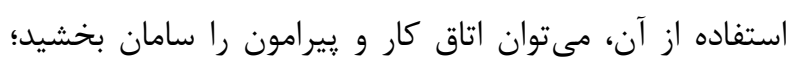

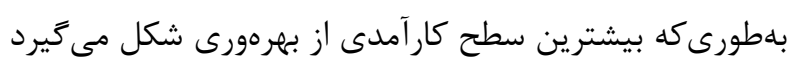

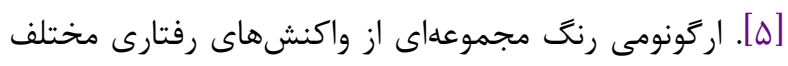

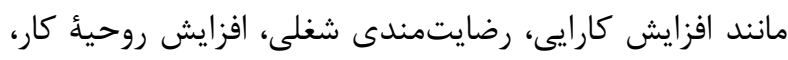

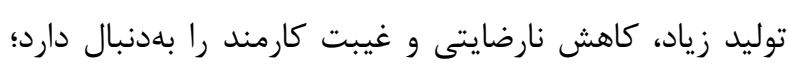

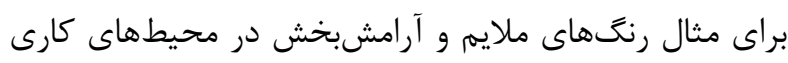

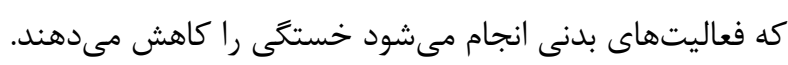

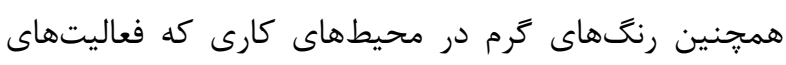

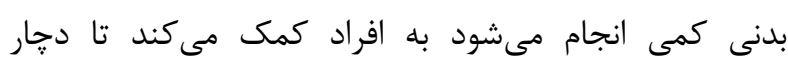

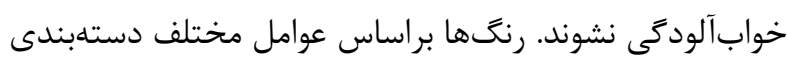


در اين مرحله شامل سال و نام نويسندگان، طراحى مطالعه، مواد و

روشها، شركت كنند
تيم تحقيق تحليل و بررسى شد. اطلاعات مورد نظر از آنها نيز استخراج و در يايگاه داده آمادشده وارد شد. اطلاعات استخراجشده

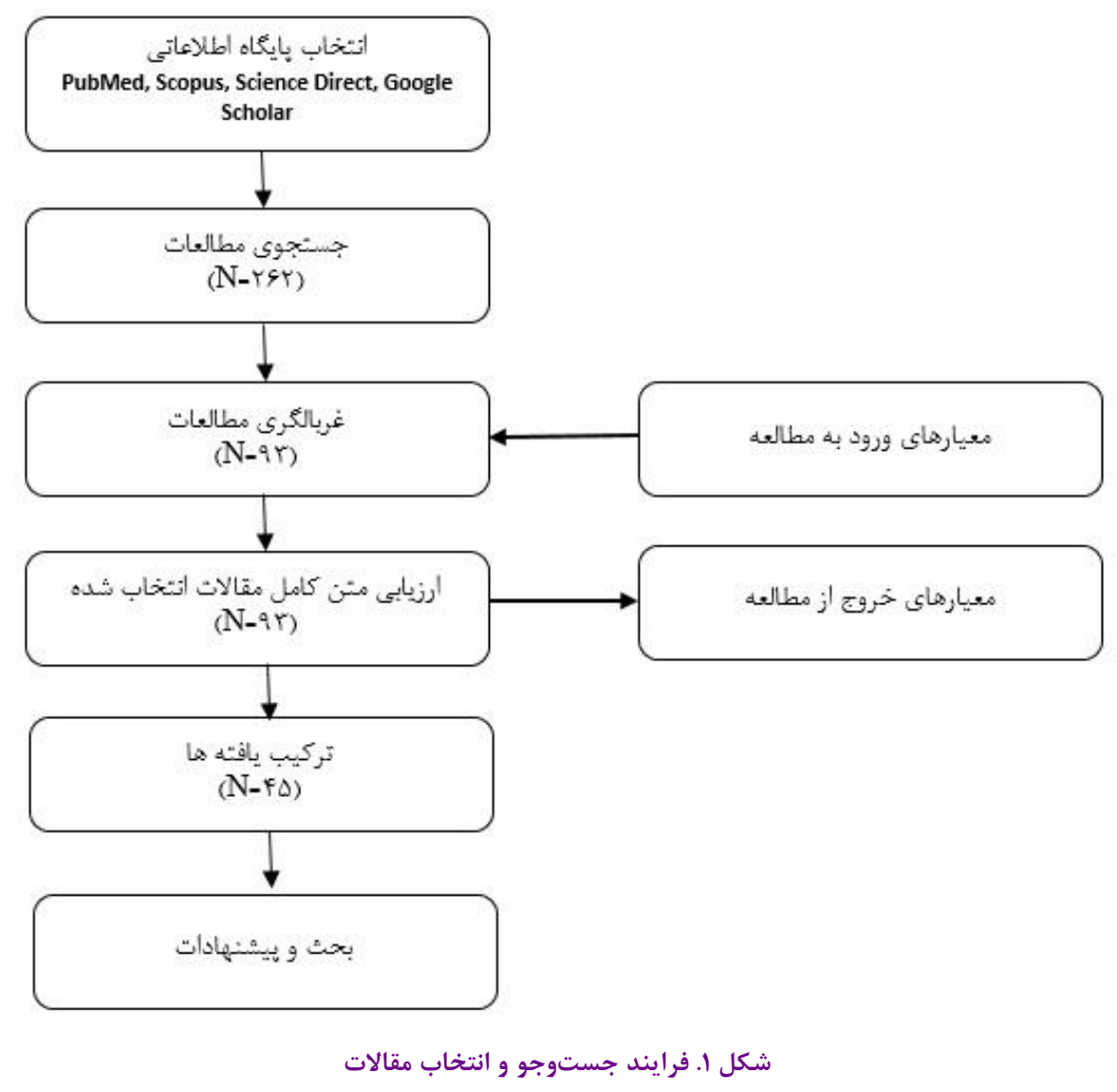

بافته ها

r. خلقوخو و احساسات: درمجموع L r مطالعه بر

خلقوخو و احساسات متمركز شده بودند. بيشتر مطالعات از يكى اندازهيرى ذهنى خلقوخو مانند فهرست بررسى جند

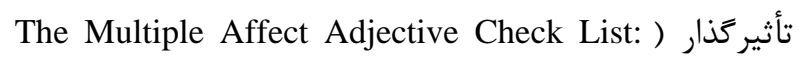

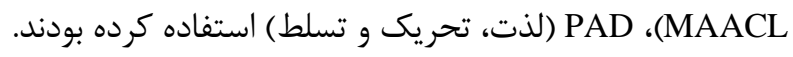
r. فيزيولوزى و بهزيستى: درمجموع \& مطالعه بر

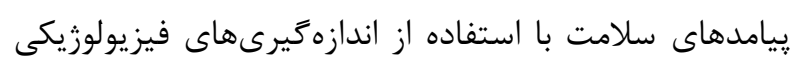
متمركز شده بودند. اين اندازهخيرىها شامل الكتروانسفالوگرام

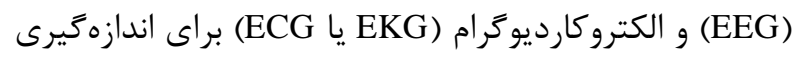

$$
\text { فعاليت مغز و تغيير ضربان قلب بود. }
$$

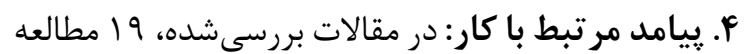
بر تأثير رنت محل كار بر ييامدهاى مرتبط با كار تمركز كرده بودند كه مىتوان آنها را به مباحث اصلى زير تقسيم كرد:

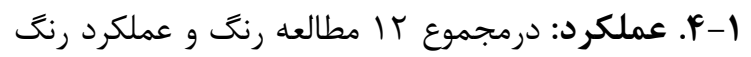

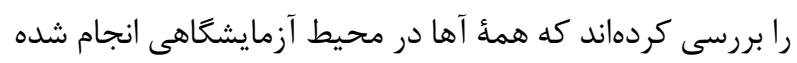

در ابتدا ب Y T مقاله از يايعاههاى اطلاعاتى مختلف شناسايى

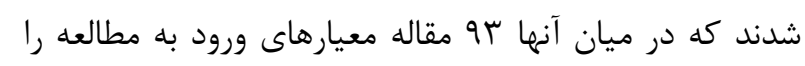

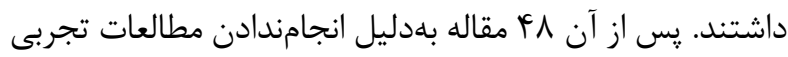
از مطالعه حذف و ه\& مقاله براى بررسى نهايى انتخاب شدند. همة مقالات در جدول ا خلاصه شدهاند. بيشتر مطالعات در مناطق غربى انجام شده است. مطالعات بينفرهنگ مفى نيز عمدتاً

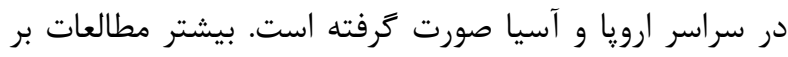
مطالعهُ رنتَهاى گرم در مقابل رنتَهاى سرد تمركز داشتند.

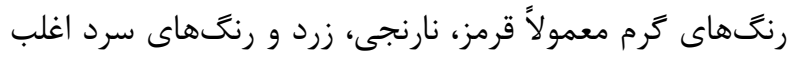

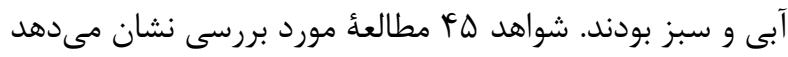

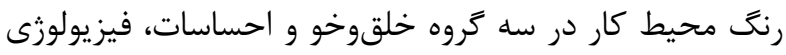

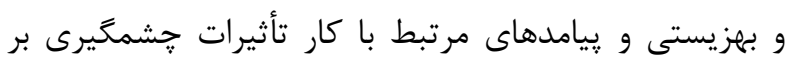

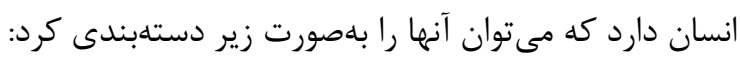

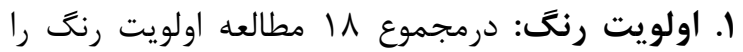
بررسى ردند. بيشتر مقالات بررسىشده، مطالعات بين فرهنگ بونى بودند. 


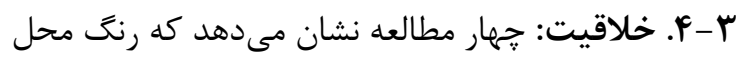

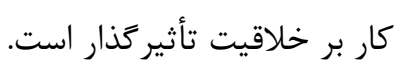

r-F

بهرهورى انسان را بر رسى كردهاند.

جدول ا. دستهبندىهاى طراحى مطالعه و تأثيرات گَزارششده از رنَ در محيط كار

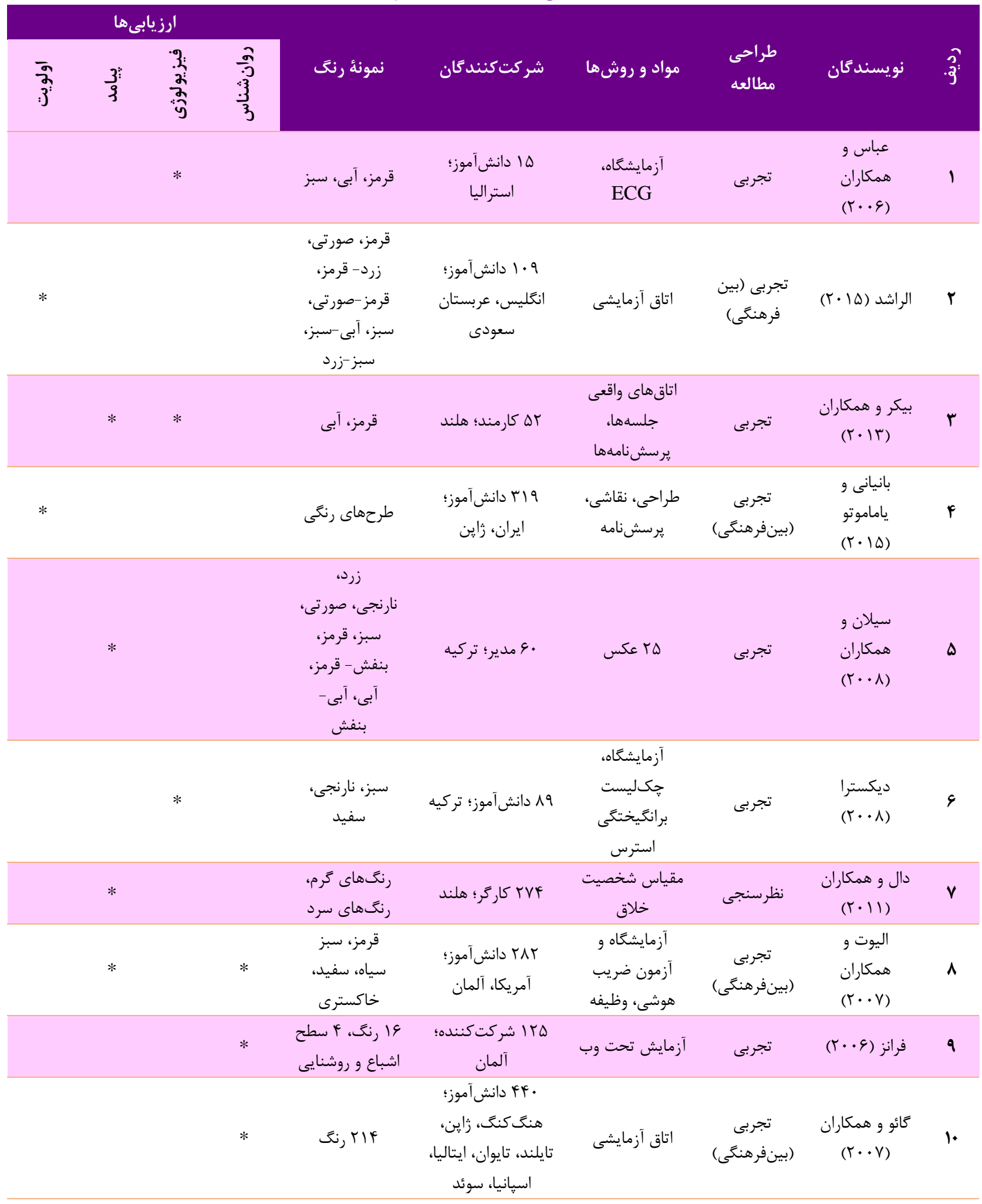




\section{ارزيابىها}

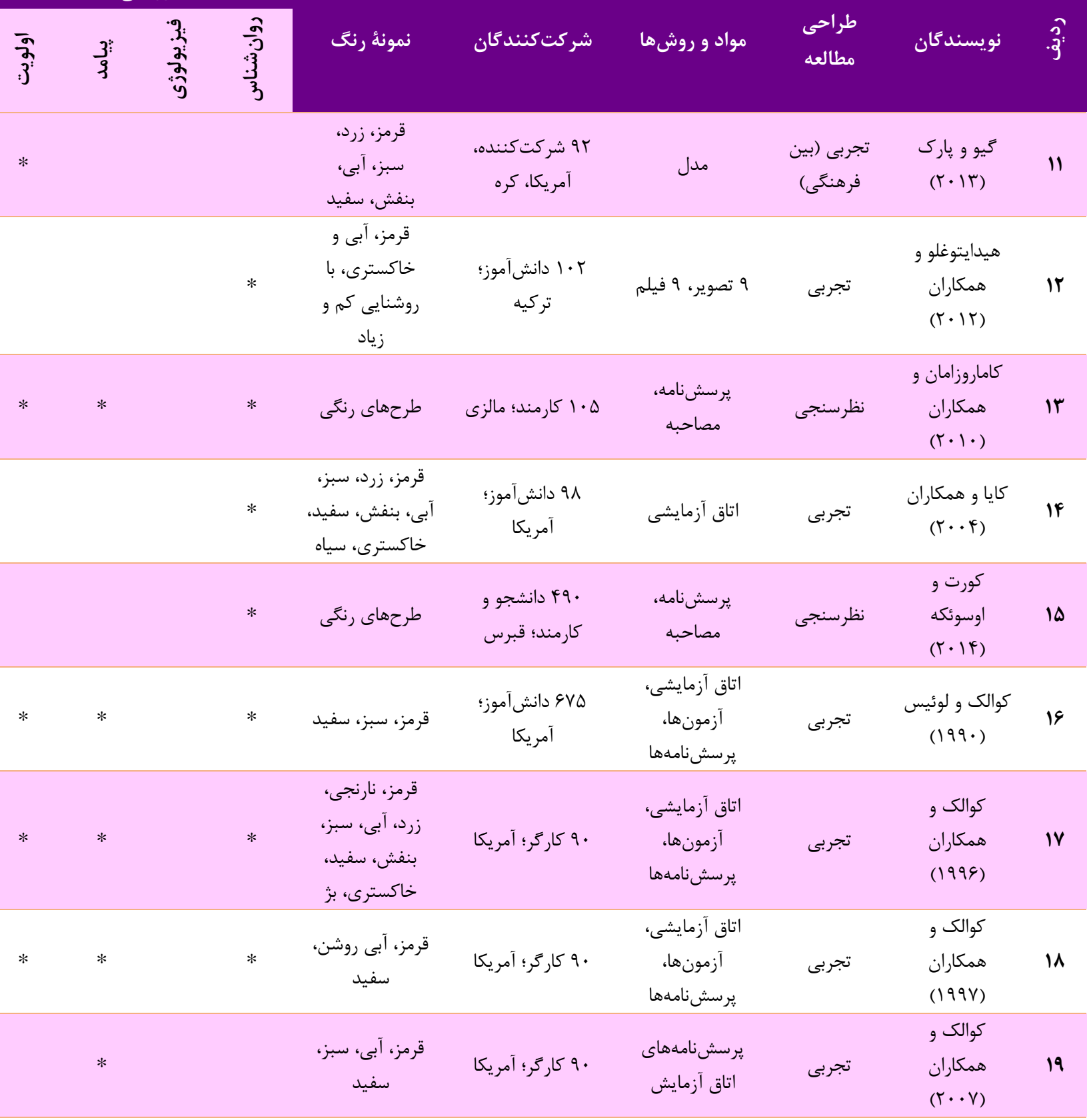

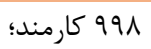

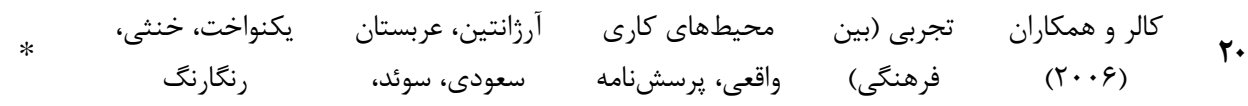

$$
\begin{aligned}
& \text { انگليس }
\end{aligned}
$$

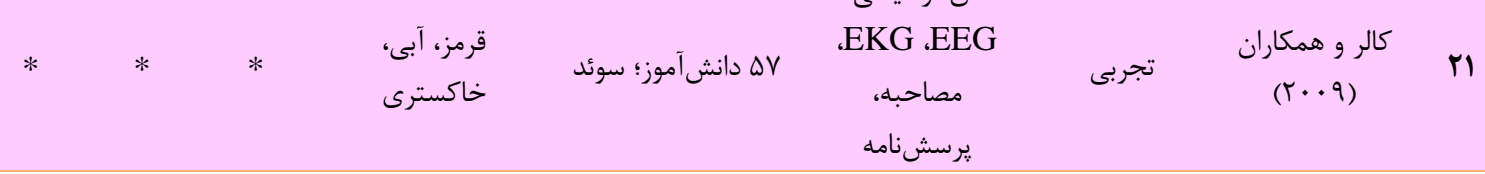

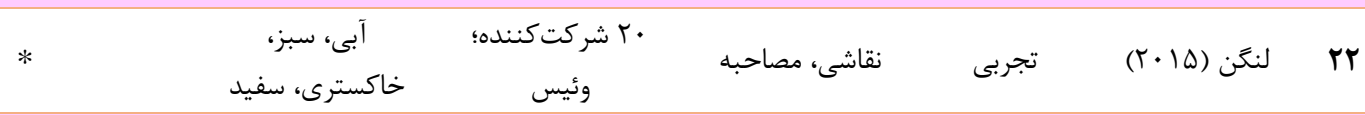$$
\text { لبدكواو }
$$

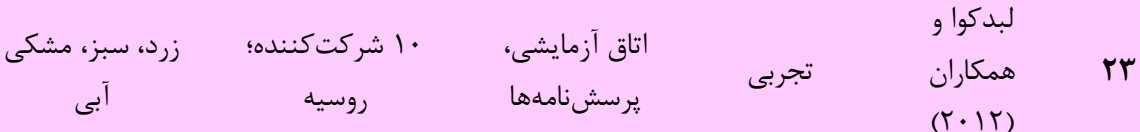




\section{ارزيابىها}

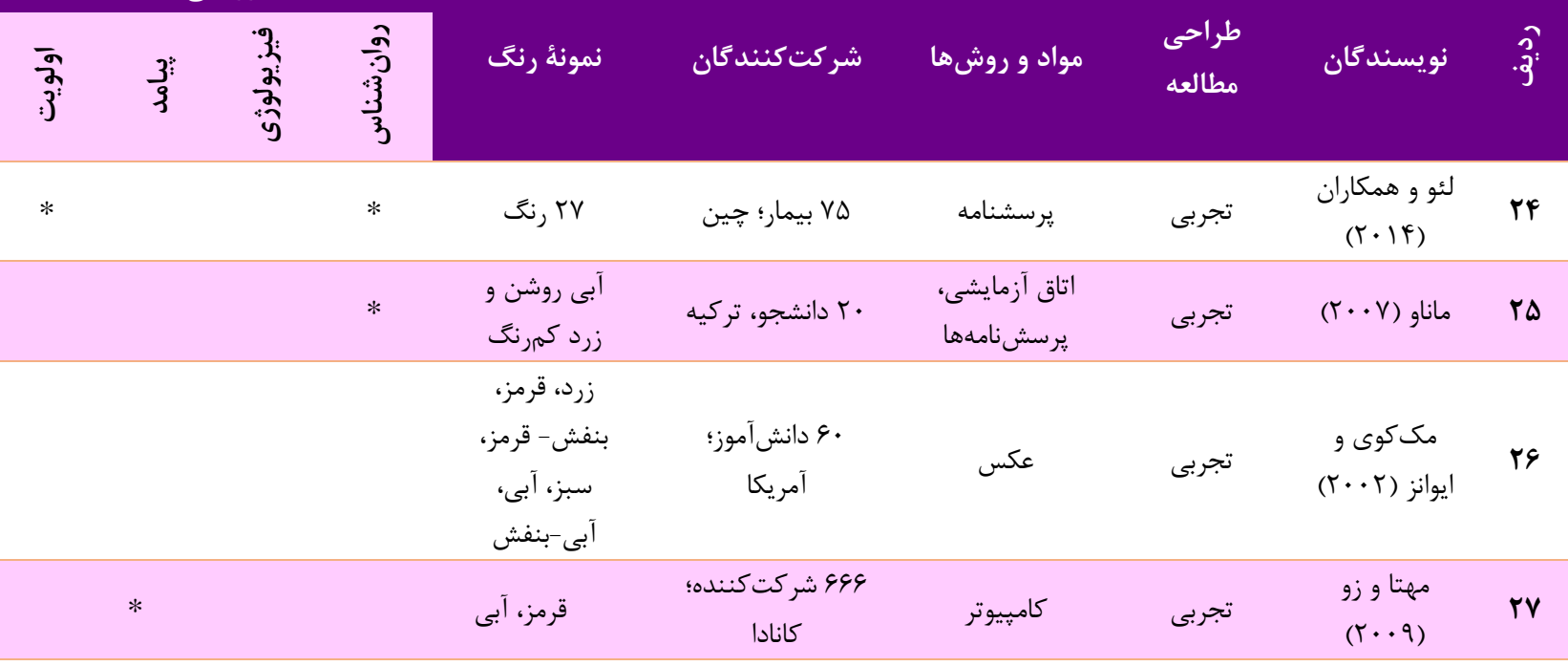

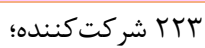

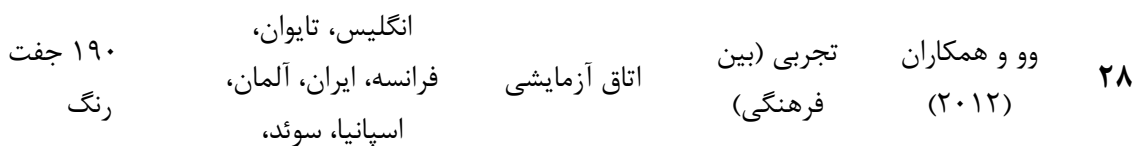
آرثانيا، سوئد،

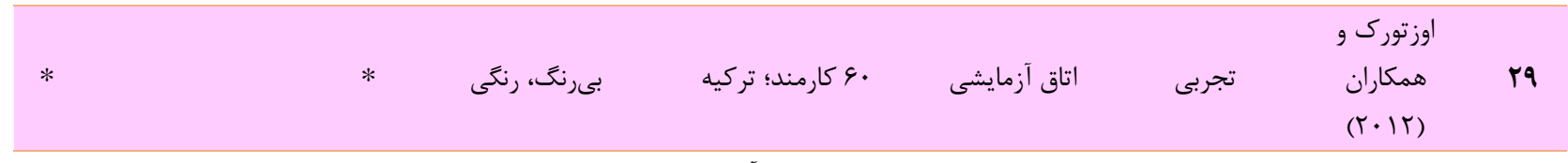

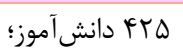

\begin{tabular}{|c|c|c|c|c|c|c|c|c|}
\hline & & $*$ & قرمز، آبى & ايالاتمتحده، & اتاق آزمايشى، & فرهربى (بين & 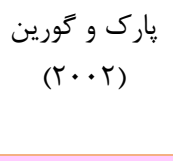 & $r$. \\
\hline & $*$ & & بن 9 قربز، آبى، زرش، سفيد، & 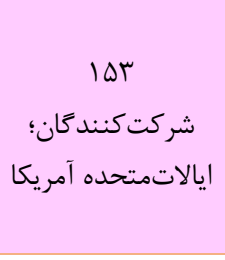 & مدل & تجربى & 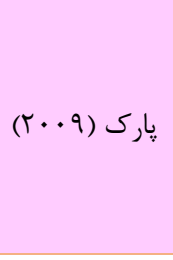 & וr \\
\hline & $*$ & & رنكى حهاى & Tايران، هند معمار؛ & يرسشنامهها & (بينفرسنجى & 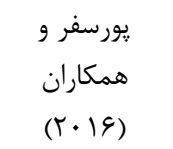 & r \\
\hline$*$ & & $*$ & 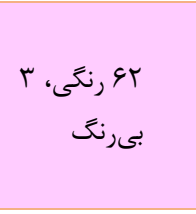 & 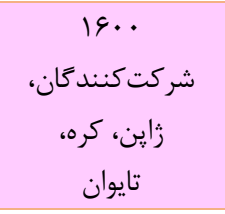 & يرسش نامهدها رنگ، & (بينفر هنغَىى) & سايتو (1999) & r \\
\hline & & $*$ & 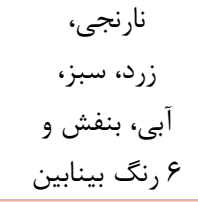 & ^• ץ شركت كننده؛ & نمودار رنغ، & نظرسنجى (بين & $\begin{array}{c}\text { سوروكوفسكى همكاران } \\
\text { و (r) }\end{array}$ & Mr \\
\hline & $*$ & & قرمز، آبى & ז ז آمانشآموز؛ & 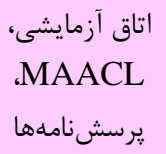 & تجربى & $\begin{array}{l}\text { استون و } \\
\text { انگليش) } \\
\text { (19919 }\end{array}$ & ra \\
\hline
\end{tabular}




\section{ارزيابىها}

$\begin{array}{llll}\overline{2} & 3 & \frac{3}{3} & \frac{2}{3} \\ 3 & 9 & \frac{3}{3} & 3 \\ 3 & 3 & 3\end{array}$

نمونهُ رنت

\section{شر كت كنندكان}

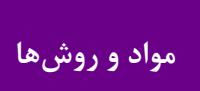

طراحى

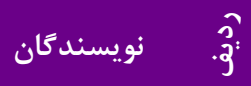

\begin{tabular}{|c|c|c|c|c|c|c|c|c|c|}
\hline & $*$ & & & سفيد، قرم، آبى & 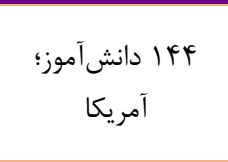 & 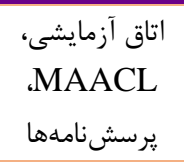 & تجربى & 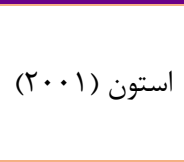 & rq \\
\hline \multirow[t]{2}{*}{$*$} & & & $*$ & قرمز، آبى & آمريكا آمآموز؛ & $\begin{array}{l}\text { يرسشنامهها آزمايشى، } \\
\text { MAACL }\end{array}$ & تجربى & 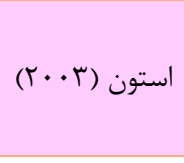 & $r v$ \\
\hline & $*$ & & $*$ & 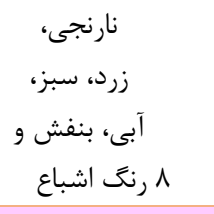 & هو شركت كننده؛ & كامييوتر & (بينفرهنكى) & 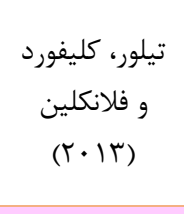 & rA \\
\hline \multirow[t]{5}{*}{$*$} & & & & 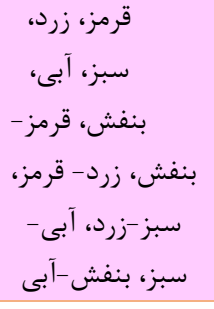 & ؟ آب دانشآموز؛ & مقياس مارتهاى رنغىى، & آزمايشى & $\begin{array}{l}\text { والدز و و (1994) } \\
\text { (19ان) }\end{array}$ & rq \\
\hline & & & $*$ & آبى، صورتى، & 9 • 9 دانشآموز؛ & 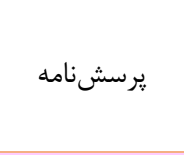 & نظرسنجى & 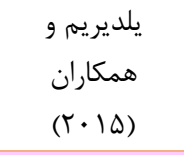 & f. \\
\hline & \multirow[t]{3}{*}{$*$} & & & سرمز، سبز و & صربستان & اتاق آزمايشى & تجربى & $\begin{array}{l}\text { زوركاو } \\
\text { همكاران } \\
(r \cdot I V)\end{array}$ & PI \\
\hline & & & $*$ & قرمز، آبى & آلمان & ير سشنامه & نظرسنجى & 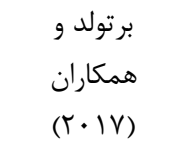 & Pr \\
\hline & & & $*$ & سياه و سفيد & بو ا شَركت كننده؛ & ״ر رششنامه & نظرسنجى & 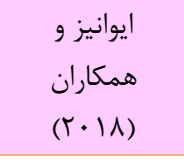 & pr \\
\hline$*$ & & & $*$ & يكنواخت & 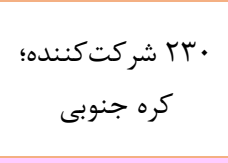 & يرسشنامه & نظرسنجى & 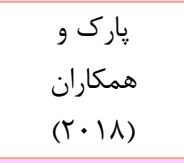 & FF \\
\hline$*$ & & & $*$ & سبز، زرد، نارنجى، & ال انمركت كننده؛ & كامييوتر & تجربى & 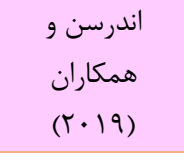 & $F \Delta$ \\
\hline 11 & 19 & 9 & $r \Delta$ & & & مجموع & & & \\
\hline
\end{tabular}

بحث

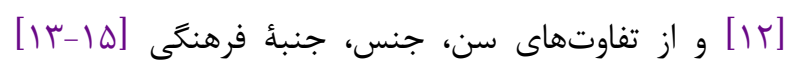

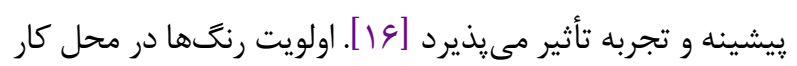

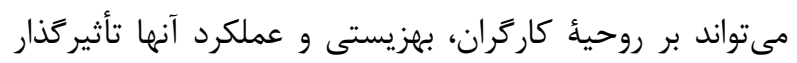

درمجموع | | مطالعه اولويت رنغ را بررسى كردهاند. بهطور

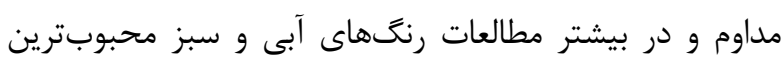

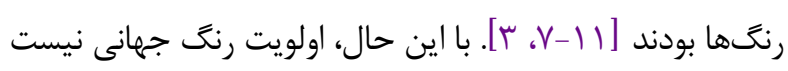


همجنين تعادل بين رنغَهاى گرم و سرد مىتواند بهرهورى را

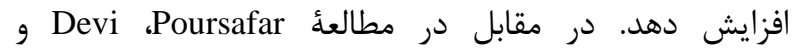
Rodrigues

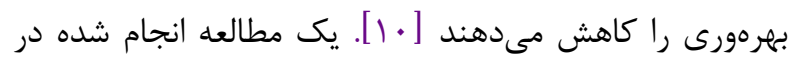

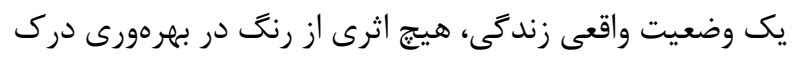

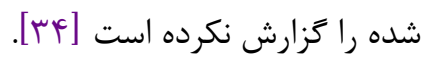

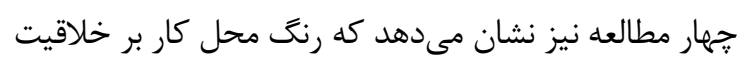

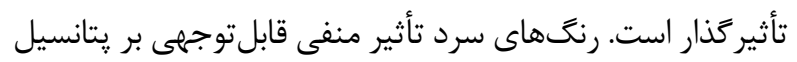

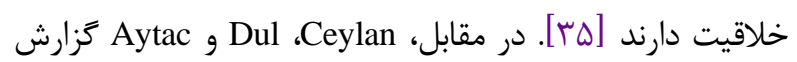
كردند كه رنغَهاى جذاب در محيط كار سبب افزايش خلائ خلاقيت

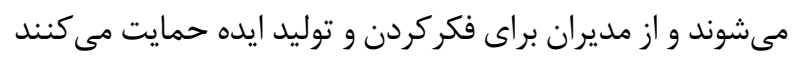

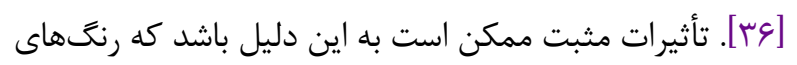

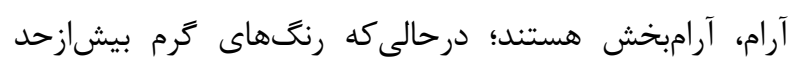

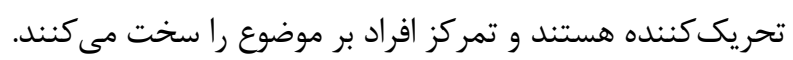

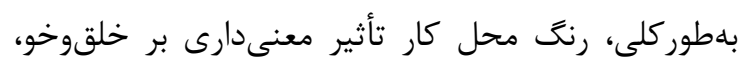

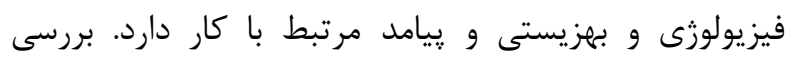

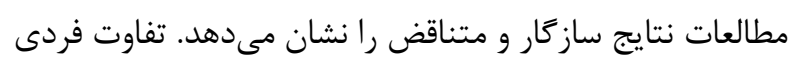

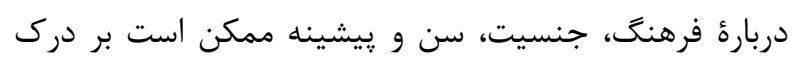

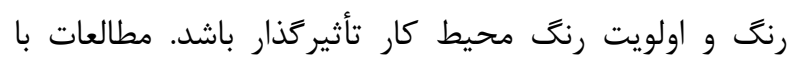

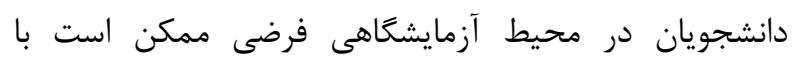

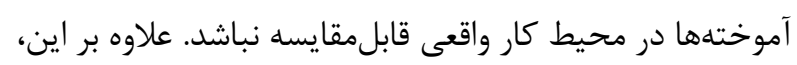

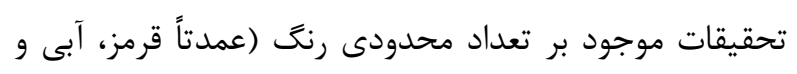

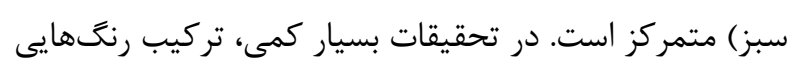

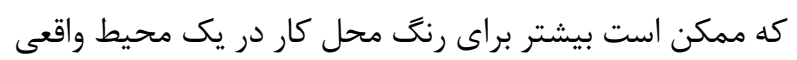
كار روزمره نمايانكر باشند، بررسى شده بـ رهاند.

\section{نتيجه كيرى}

براساس يافتههاى مطالعه، ثابت شد كه رنگ محيط كار نقش

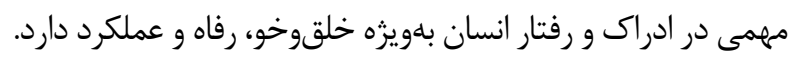
استفاده از رنخ در محيط كار مى تواند سبب افزايش روحيئ مثبت،

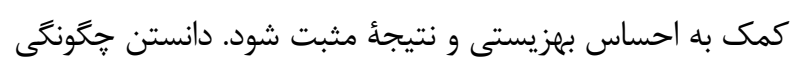

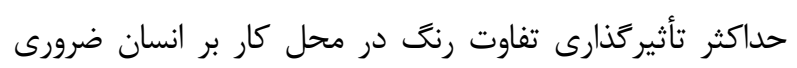
است. براى بررسى عوامل تركيب رنغ، زمينٔه محيط كار، عوامل بين فرهنگ و تفاوتهاى فردى، تحقيقات بيشترى لازم است.

\section{تقدير و تشكر}

بدينوسيله از همؤ عزيزانى كه به ما را در نوشتن اين مقاله

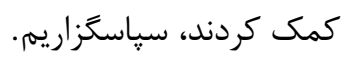

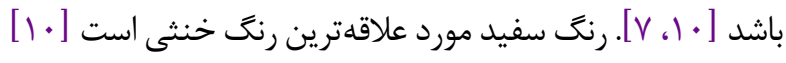

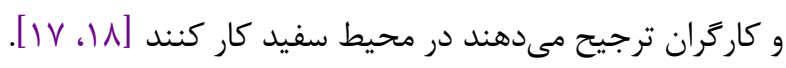

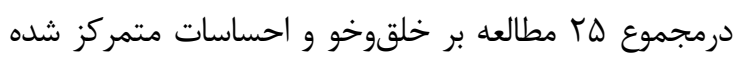

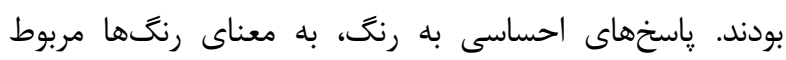

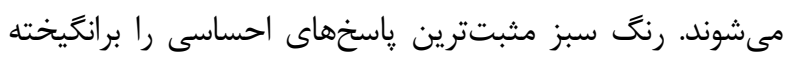

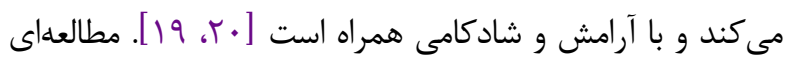

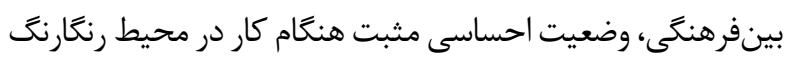

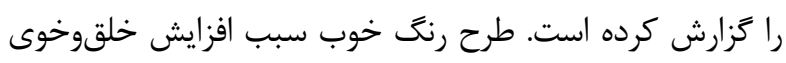

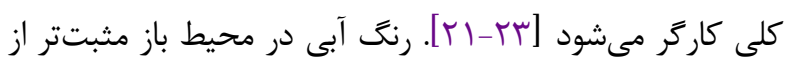

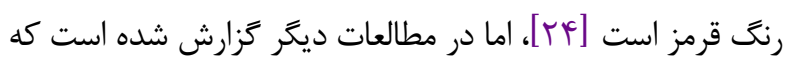

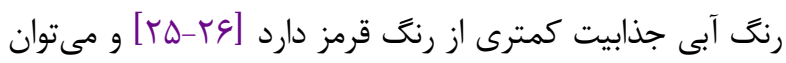

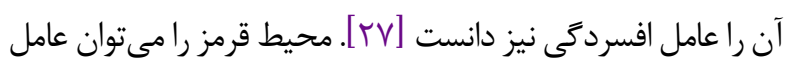

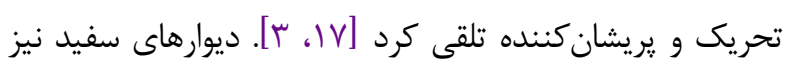

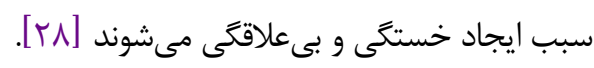

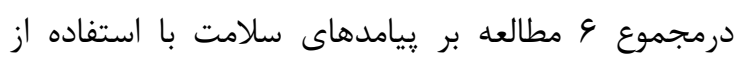

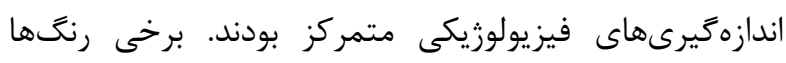

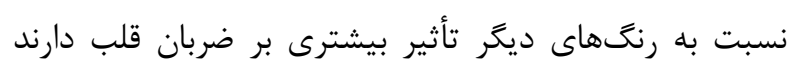

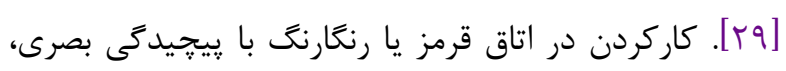

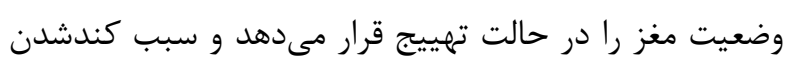

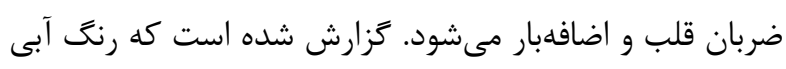

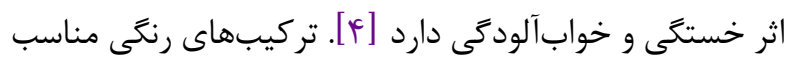

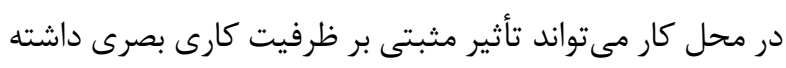

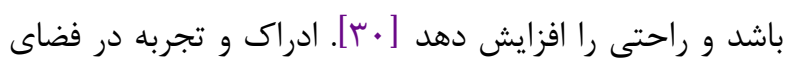

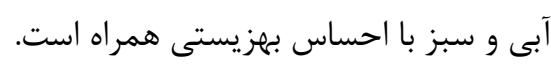

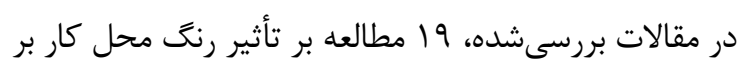

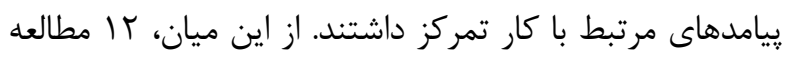

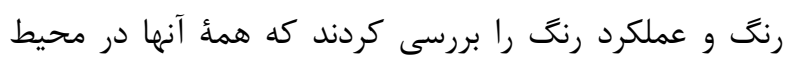

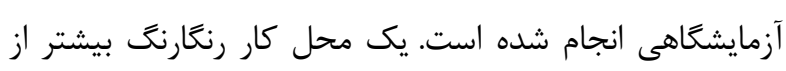

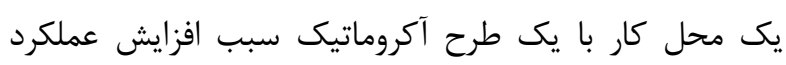

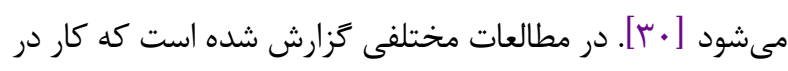

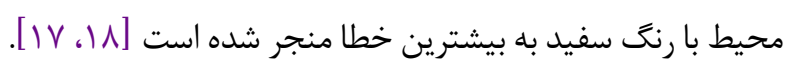

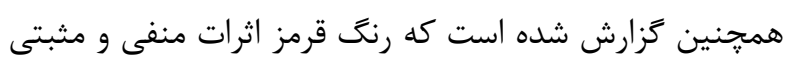

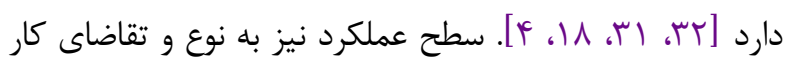

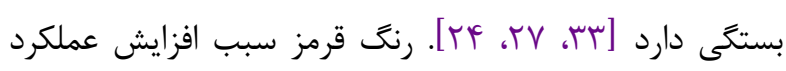

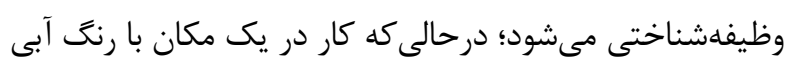

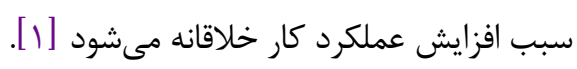

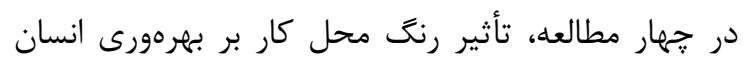

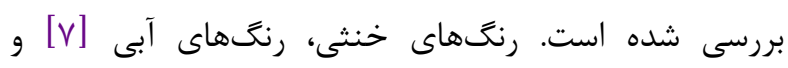


منابع مالى

منابع مالى اين مطالعه توسط نويسندگان تامين شده است.

\section{References}

1. Mehta R, Zhu RJ. Blue or red? Exploring the effect of color on cognitive task performances. Science. 2009 Feb [DOI:10.1126/science.1169144] [PMID] 27;323(5918):1226-9.

2. Kwallek N, Soon K, Lewis CM. Work week productivity, visual complexity, and individual environmental sensitivity in three offices of different color interiors. Color Research \& Application: Endorsed by Inter-Society Color Council, The Colour Group (Great Britain), Canadian Society for Color, Color Science Association of Japan, Dutch Society for the Study of Color, The Swedish Colour Centre Foundation, Colour Society of Australia, Centre Français de la Couleur. 2007 Apr;32(2):130-43. [DOI:10.1002/col.20298]

3. Kwallek N, Woodson H, Lewis CM, Sales C. Impact of three interior color schemes on worker mood and performance relative to individual environmental sensitivity. Color Research \& Application: Endorsed by Inter-Society Color Council, The Colour Group (Great Britain), Canadian Society for Color, Color Science Association of Japan, Dutch Society for the Study of Color, The Swedish Colour Centre Foundation, Colour Society of Australia, Centre Français de la Couleur. 1997 Apr;22(2):121-32. [DOI:10.1002/(SICI)15206378(199704)22:23.0.CO;2-V]

4. Küller R, Mikellides B, Janssens J. Color, arousal, and performance-A comparison of three experiments. Color Research \& Application: Endorsed by Inter-Society Color Council, The Colour Group (Great Britain), Canadian Society for Color, Color Science Association of Japan, Dutch Society for the Study of Color, The Swedish Colour Centre Foundation, Colour Society of Australia, Centre Français de la Couleur. 2009 Apr;34(2):141-52. [DOI:10.1002/col.20476]

5. Brooker A, Franklin A. The effect of colour on children's cognitive performance. British Journal of Educational Psychology. 2016 Jun;86(2):241-55. [DOI:10.1111/bjep.12101] [PMID]

6. Elliot AJ. Color and psychological functioning: a review of theoretical and empirical work. Frontiers in psychology. $\quad 2015 \quad$ Apr $2 ; 6: 368$. [DOI:10.3389/fpsyg.2015.00368] [PMID] [PMCID]

7. Kamaruzzaman SN, Zawawi EM. Influence of employees' perceptions of colour preferences on productivity in Malaysian office buildings. Journal of Sustainable Development. 2010 Sep 1;3(3):283. [DOI:10.5539/jsd.v3n3p283]

8. Liu W, Ji J, Chen H, Ye C. Optimal color design of psychological counseling room by design of experiments and response surface methodology. PloS one. $2014 \quad$ Mar 4;9(3):e90646. [DOI:10.1371/journal.pone.0090646] [PMID] [PMCID]

\author{
تعارض منافع \\ بين نويسندكان هيجَّونه تعارضى در منافع وجود ندارد.
}

9. Park JG. Color perception in pediatric patient room design: Healthy children vs. pediatric patients. HERD: Health Environments Research \& Design Journal. 2009 Apr;2(3):6-28. [DOI:10.1177/193758670900200302] [PMID]

10. Poursafar Z, Devi NR, Rodrigues LR. EVALUATION OF COLOR AND LIGHTING PREFERENCES IN ARCHITECTS'OFFICES FOR ENHANCING PRODUCTIVITY. International Journal of Current Research and Review. 2016 Feb 1;8(3):1.

11. Valdez P, Mehrabian A. Effects of color on emotions. Journal of experimental psychology: General. 1994 Dec;123(4):394. [DOI:10.1037/0096-3445.123.4.394] [PMID]

12. Taylor C, Clifford A, Franklin A. Color preferences are not universal. Journal of Experimental Psychology: General. $2013 \quad$ Nov;142(4):1015. [DOI:10.1037/a0030273] [PMID]

13. Park Y, Guerin DA. Meaning and preference of interior color palettes among four cultures. Journal of interior design. 2002 May;28(1):27-39. [DOI:10.1111/j.19391668.2002.tb00370.x]

14. Saito M. Comparative studies on color preference in Japan and other Asian regions, with special emphasis on the preference for white. Color Research \& Application. 1996 Feb;21(1):35-49. [DOI:10.1002/(SICI)15206378(199602)21:13.0.CO;2-6]

15. Sorokowski P, Sorokowska A, Witzel C. Sex differences in color preferences transcend extreme differences in culture and ecology. Psychonomic bulletin \& review. 2014 Oct 1;21(5):1195-201. [DOI:10.3758/s13423-014-0591-8] [PMID] [PMCID]

16. Baniani M, Yamamoto S. A comparative study on correlation between personal background and interior color preference. Color Research \& Application. 2015 Aug;40(4):416-24. [DOI:10.1002/col.21906]

17. Kwallek N, Lewis CM. Effects of environmental colour on males and females: A red or white or green office. Applied ergonomics. 1990 Dec 1;21(4):275-8. [DOI:10.1016/0003-6870(90)90197-6]

18. Kwallek N, Lewis CM, Lin-Hsiao JW, Woodson H. Effects of nine monochromatic office interior colors on clerical tasks and worker mood. Color Research \& Application. $\quad 1996 \quad$ Dec;21(6):448-58. [DOI:10.1002/(SICI) 15206378(199612)21:63.0.CO;2-W]

19. NAz KA, Epps H. Relationship between color and emotion: A study of college students. College Student J. 2004 Sep;38(3):396.

20. Andersen E, Maier A. The attentional guidance of individual colours in increasingly complex displays. Applied ergonomics. 2019 Nov 1;81:102885. [DOI:10.1016/j.apergo.2019.102885] [PMID]

21. Küller R, Ballal S, Laike T, Mikellides B, Tonello G. The impact of light and colour on psychological mood: a cross-cultural study of indoor work environments. 
Ergonomics. 2006 Nov 15;49(14):1496-507. [DOI:10.1080/00140130600858142] [PMID]

22. Rizomyliotis I, Konstantoulaki K, Kostopoulos I. Reassessing the effect of colour on attitude and behavioural intentions in promotional activities: The moderating role of mood and involvement. Australasian Marketing Journal (AMJ). 2018 Aug 1;26(3):204-15. [DOI:10.1016/j.ausmj.2018.04.002]

23. Park CW, Bae G. The Effects of Uniform Color and Restaurant Type on Behavioral Intention: The Comparison between the Employees' Perception and Customers' Perception in the Foodservice Industry. Culinary Science \& Hospitality Research. 2018 Sep;24(7):89-95. [DOI:10.20878/cshr.2018.24.7.010]

24. Stone NJ. Designing effective study environments. Journal of environmental psychology. 2001 Jun 1;21(2):179-90. [DOI:10.1006/jevp.2000.0193]

25. Yildirim K, Cagatay K, Ayalp N. Effect of wall colour on the perception of classrooms. Indoor and Built Environment. $2015 \quad$ Aug;24(5):607-16. [DOI:10.1177/1420326X14526214]

26. Berthold A, Reese G, Martin J. The effect of red color on perceived self-attractiveness. European Journal of Social Psychology. 2017 Aug;47(5):645-52. [DOI:10.1002/ejsp.2238]

27. Stone NJ, English AJ. Task type, posters, and workspace color on mood, satisfaction, and performance. Journal of Environmental Psychology. 1998 Jun 1;18(2):175-85. [DOI:10.1006/jevp.1998.0084]

28. Kurt S, Osueke KK. The effects of color on the moods of college students. SAGE Open. 2014 Feb 27;4(1):2158244014525423. [DOI:10.1177/2158244014525423]

29. Abbas N, Kumar D, Mclachlan N. The psychological and physiological effects of light and colour on space users. In2005 IEEE Engineering in Medicine and Biology 27th Annual Conference 2006 Jan 17 (pp. 1228-1231).

IEEE. [DOI:10.1109/IEMBS.2005.1616646] [PMID]

30. Lebedkova SM, Panteleeva NS, Stepanova IV. INFLUENCE ON VISUAL WORKING CAPACITY OF COLOUR DECORATION OF THE WORKPLACE FOR WORK WITH A COMPUTER. Light \& Engineering. 2012 Jul 1;20(3).

31. Elliot AJ, Maier MA, Moller AC, Friedman R, Meinhardt J. Color and psychological functioning: The effect of red on performance attainment. Journal of experimental psychology: General. 2007 Feb;136(1):154. [DOI:10.1037/0096-3445.136.1.154] [PMID]

32. Vuković ZK, Petrović IB. THE EFFECT OF RED COLOR ON ANAGRAM PERFORMANCEREPLICATION OF EXPERIMENT1. EMPIRICAL STUDIES IN PSYCHOLOGY. 2017 Mar 24:10.

33. Stone NJ. Environmental view and color for a simulated telemarketing task. Journal of Environmental Psychology. $2003 \quad$ Mar 1;23(1):63-78. [DOI:10.1016/S0272-4944(02)00107-X]

34. Bakker I, van der Voordt TJ, de Boon J, Vink P. Red or blue meeting rooms: does it matter?. Facilities. $2013 \mathrm{Jan}$ 25. [DOI:10.1108/02632771311292527]

35. McCoy JM, Evans GW. The potential role of the physical environment in fostering creativity. Creativity
Research Journal. 2002 Oct 1;14(3-4):409-26. [DOI:10.1207/S15326934CRJ1434 11]

36. Ceylan C, Dul J, Aytac S. Can the office environment stimulate a manager's creativity?. Human Factors and ergonomics in Manufacturing \& service Industries. 2008 Nov;18(6):589-602. [DOI:10.1002/hfm.20128] 